\title{
Characteristics and Behaviour of Transient Current during Fault Occurrence on Hybrid Overhead line and Underground Cable Distribution System
}

\author{
Tussanai Satharpornmongkollert ${ }^{\mathrm{a}}$, Atthapol Ngaopitakkul ${ }^{\mathrm{a},{ }^{*}}$, Chaichan Pothisarn ${ }^{\mathrm{a}}$ \\ ${ }^{\text {a }}$ Faculty of Engineering, King Mongkut's Institute of Technology Ladkrabang, \\ Chalongkrung Road,Ladkrabang, Bangkok 10520, Thailand. \\ *Corresponding Author: knatthap@kmitl.ac.th
}

\begin{abstract}
This paper proposes to study characteristics of distribution system consisting of overhead line and underground cable in a system when single line to ground fault occurs in the system. For this study, ATP/EMTP simulation is used to simulate current waveform in each case as overhead system, underground system and both of underground and overhead systems, called hybrid system. The current waveform is measured at sending end side for analysis when fault occurs. Then, compare the hybrid system result with overhead and underground system results for observing different points. The characteristics from analysis are used to plan and design system protection and determine correctly protection equipment operations.
\end{abstract}

Keywords: Fault characteristic, Distribution system, Hybrid, Overhead line, Underground cable, Fault.

\section{INTRODUCTION}

Nowadays, Thailand electricity demand has rapidly increased as same as global developing and population is increasing so, the electricity has to be more produced in order to meet electrical energy demand. Distribution system, which is served to send electrical energy from substation to end users, must also be expanded for support. In the past, Thailand distribution system used only overhead line for sending electrical energy but today, because of location and practicability such as crossing railway lines and passing through environmentally sensitive areas, Thailand's electricity authority will replace overhead cable with underground one.
Moreover, underground cable, which is set up in electrical power system, changes overall system from overhead line system to hybrid system. It affects to plan and design protection system including protection equipment. Hence, this paper focuses on fault's behavior in hybrid distribution system for analyzing system characteristics, which will be used to develop protection system in the next stage. For system protection setup and design, fault location is one parameter used to analyze with protection equipment as relay. About studying fault location indentifying method in the past researches, there have been many methods such as using fuzzy logic for analyzing fault location (1), measuring parameter from system as voltage, current ${ }^{(2)-(4)}$, impedance $^{(5)-(6)}$ and phasor ${ }^{(7)}$, or measuring traveling wave from starting and ending points of distribution line ${ }^{(8)}$ as used Park's Transformation to transfer 3 phases current to 2 phase DC current for finding differential value of waveform (9), design location fault method from travelling wave in distribution system containing series capacitor for power factor increasing ${ }^{(10)}$, fault locating efficiently between hybrid distribution system and overhead line by travelling wave studying ${ }^{(11)}$. From the above methods, this paper focuses on current traveling wave method for characteristic study of system when fault occurs.

This paper proposes to study waveform behavior and characteristics when fault occurs in distribution system, consisting of overhead line and underground cable for sending. The fault simulation in this paper is set up to create single line to ground fault in ATP/EMTP simulation program and change fault position and fault's angle for behavior analysis by reading out signal from sending end point of distribution line. 


\section{Simulation MODEL DeSIGN}

For simulation model design, this paper used $115 \mathrm{kV}$ distribution line systems from Provincial Electricity Authority (PEA). The simulation in ATP/EMTP is divided into 3 models with specifications of overhead line and underground cable as follows:

(I) Overhead line system as shown in Fig. 1(a):

- 22 meters reinforced concrete pole.

- Conductor Type: AAC $400 \mathrm{~mm}$.

- Total line distance is $40 \mathrm{~km}$.

(II) Underground cable as shown in Fig. 1(b):

- Depth of laying conduits 1.5 meters from the ground.

- Conduit of $160 \mathrm{~mm}$.

- Underground cables diameter is $800 \mathrm{~mm}$. Insulation XLPE.

- 1 of cable per pipe.

- Total line distance is $40 \mathrm{~km}$.

(III) Hybrid system as shown in Fig. 1(c):

- Overhead line system in (I) and underground cable system in (II).

- Each line distance of overhead line and underground cable is $20 \mathrm{~km}$.

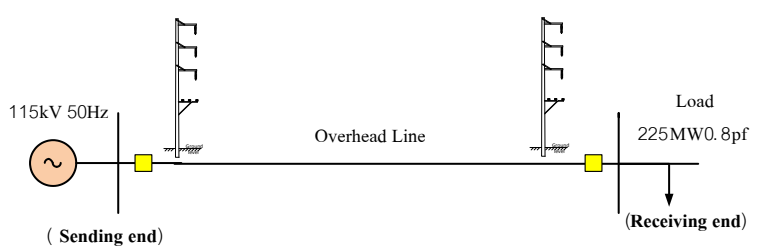

(a) Overhead system

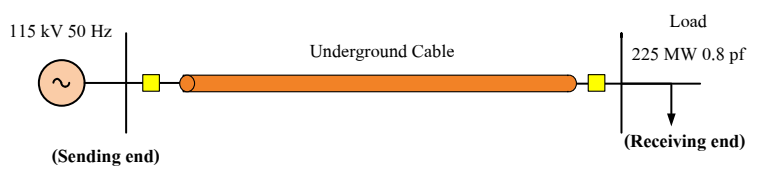

(b) Underground system

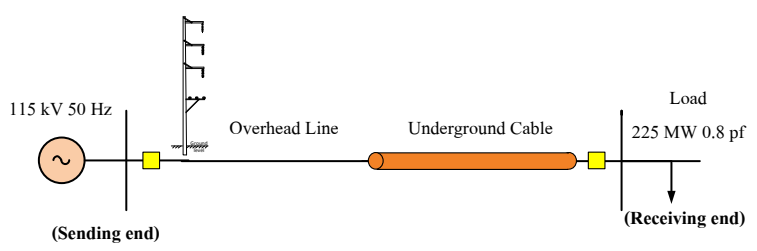

(c) Hybrid system

Fig.1. the real distribution system with 50 MVA transformers.
Fault simulation is set up at 40 milliseconds, then change fault's distance and fault's angle for investigation.

- Fault's angle at $0^{\circ}$ and $60^{\circ}$ by comparing with Phase A voltage angle.

- Fault's position at $20 \%-80 \%$ of total line distance.

- Fault occurring in 3 systems as overhead system, underground system and hybrid system.

\section{Simulation Result}

In this section, the case studies of simultaion were performed to study the characteristics of fault current waveform. The signal is simulated from EMTP/ATPDraw by using sampling rate at $100 \mathrm{kHz}$ and employing switch for determining fault's occuring time. In this paper, we set start time at 0.04 second and simulate overall signal in 5 cycles (0-0.1s) after fault occurrence, then focus on result of the single-line to ground fault occurrence when the fault inception angle and fault location are changed.

By changing fault's location at $20 \%$ of line distance as shown in Table 1 and Fig. 2, in normal state overhead system current waveform amplitude is $324.8 \mathrm{~A}$. When fault occurs, the current increases immediately and the maximum current is $1.531 \mathrm{kA}$ that is in negative value because of effect from fault inception angle. This trend is compared with underground and hybrid system result; all results of 3 systems seem to have similar trend. The pre-fault current of underground and hybrid system is 328.4 and 327.5, respectively. While post-fault maximum current of both system are $1.579 \mathrm{kA}$ and $1.531 \mathrm{kA}$. By changing fault's location at $40 \%$ as shown in Table 1 and Fig. 3, the result shows that it has a similar trend as previously mentioned, but slightly different in current value which slightly decreases because of system impedance change. This changing is also occurred with $60 \%$ and $80 \%$ of line distance as shown in Figs. 4 and 5 respectively.

When comparing simulation result at $20 \%, 40 \%, 60 \%$, and $80 \%$ as show in Fig. 6, we notice that the current waveform of 3 systems tends to decrease when fault's position is far from substation. And when considering fault's location at $20 \%$ and $40 \%$ of distance, it is found that overhead system current and hybrid current are similar because of $20 \%$ and $40 \%$ of both systems are same position during fault occurrence. While considering underground and hybrid system at $60 \%$ and $80 \%$ of line distance, both of currents are not the same because in hybrid system, impedance is combined between overhead and underground parameter value after $50 \%$ of line distance. 


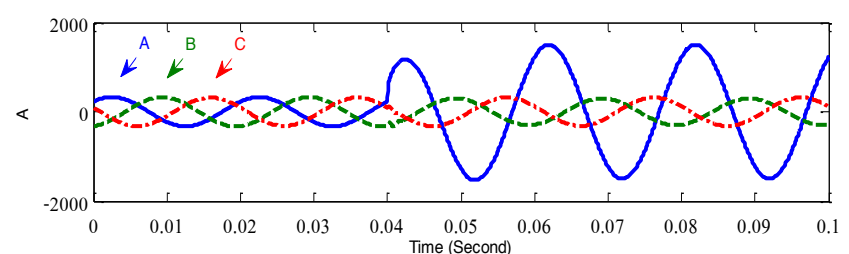

(a) Overhead system

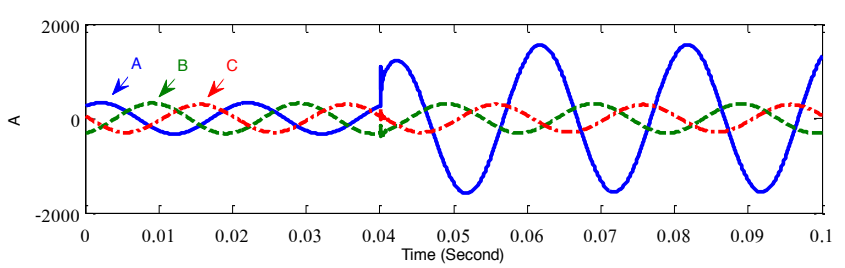

(b) Underground system

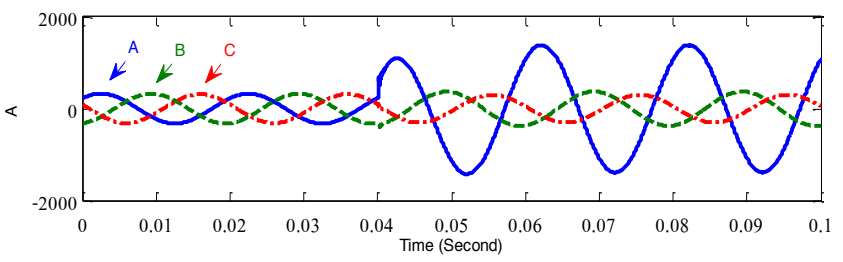

(c) Hybrid system

Fig. 2. $20 \%$ of line distance in single line to ground fault

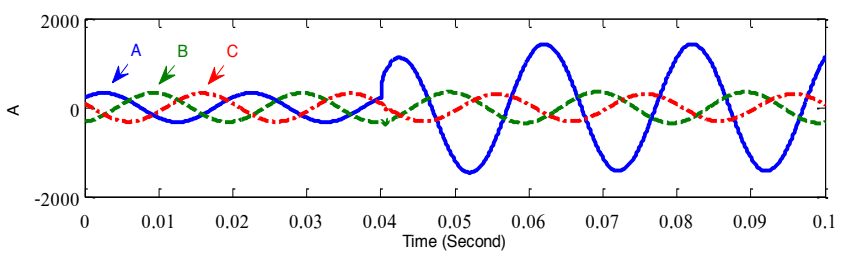

(a) Overhead system

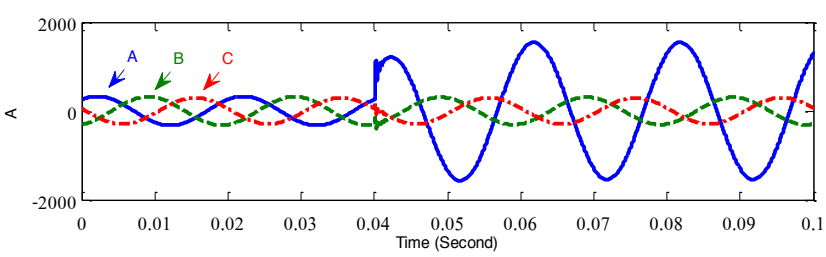

(b) Underground system

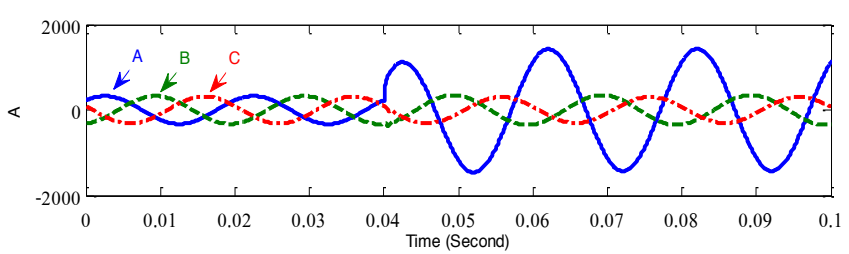

(c) Hybrid system

Fig. $3.40 \%$ of line distance in single line to ground fault

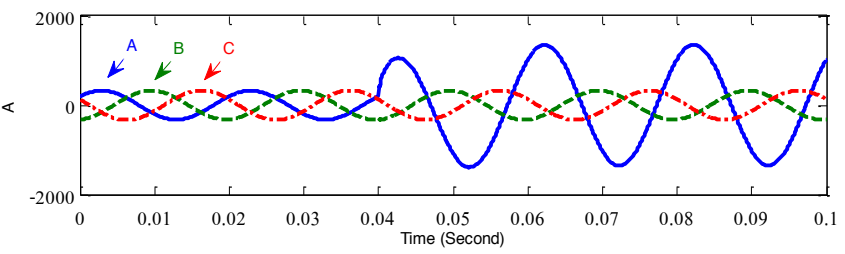

(a) Overhead system

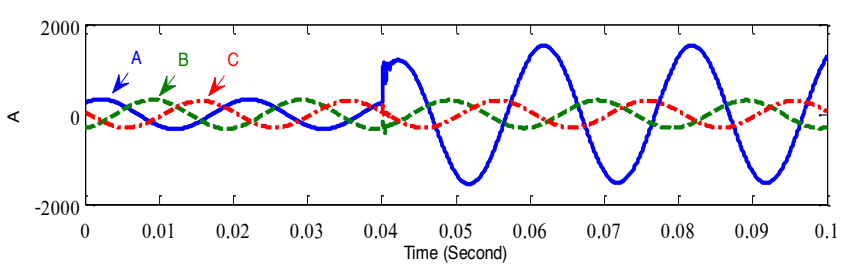

(b) Underground system

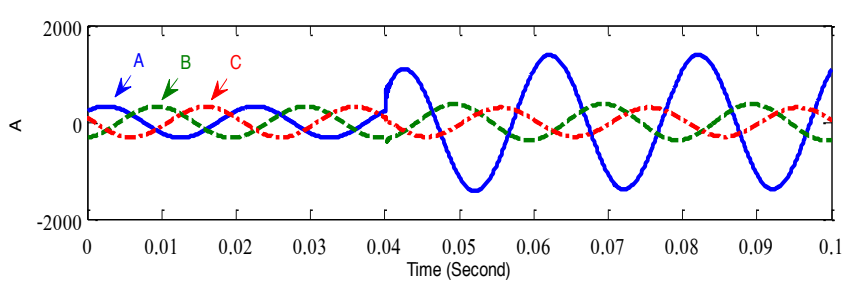

(c) Hybrid system

Fig. 4. $60 \%$ of line distance in single line to ground fault

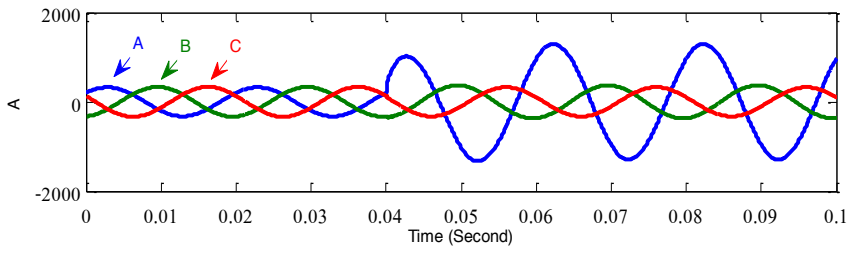

(a) Overhead system

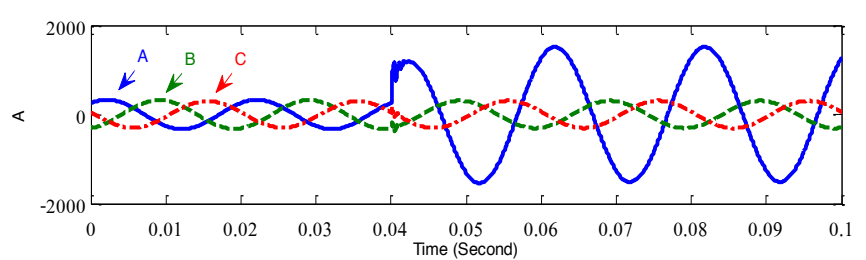

(b) Underground system

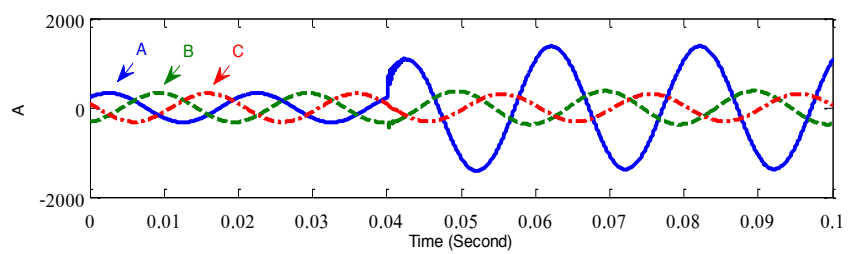

(c) Hybrid system

Fig. $5.80 \%$ of line distance in single line to ground fault 
Table 1. The maximum amplitude of current during pre- and post-fault condition for various distances in overhead line distribution system.

\begin{tabular}{|c|c|c|c|c|c|c|c|}
\hline \multirow{2}{*}{$\begin{array}{c}\text { Line } \\
\text { distance }\end{array}$} & $\begin{array}{c}\text { Inception } \\
\text { angle }\end{array}$ & \multicolumn{2}{|c|}{ Overhead system } & \multicolumn{2}{c|}{ Underground system } & \multicolumn{2}{c|}{ Hybrid system } \\
\cline { 3 - 8 }$(\%)$ & $\left({ }^{\circ}\right)$ & Pre-fault & Post-fault & Pre-fault & Post-fault & Pre-fault & Post-fault \\
\hline 20 & 0 & 324.8 & 1531 & 328.4 & 1579 & 327.5 & 1531 \\
\hline 40 & 0 & 324.8 & 1462 & 328.4 & 1569 & 327.5 & 1462 \\
\hline 60 & 0 & 324.8 & 1389 & 328.4 & 1554 & 327.5 & 1424 \\
\hline 80 & 0 & 324.8 & 1331 & 328.4 & 1538 & 327.5 & 1411 \\
\hline
\end{tabular}

Table 2. The maximum amplitude of current during pre- and post-fault condition for various angles in overhead line distribution system.

\begin{tabular}{|c|c|c|c|c|c|c|c|}
\hline \multirow{2}{*}{$\begin{array}{c}\text { Line } \\
\text { distance }\end{array}$} & Inception & \multicolumn{2}{|c|}{ Overhead system } & \multicolumn{2}{|c|}{ Underground system } & \multicolumn{2}{|c|}{ Hybrid system } \\
\cline { 3 - 8 } & angle & Pre-fault & Post-fault & Pre-fault & Post-fault & Pre-fault & Post-fault \\
\hline 20 & 0 & 324.8 & 1531 & 328.4 & 1579 & 327.5 & 1531 \\
\hline 20 & 60 & 324.8 & 1605 & 328.4 & 1652 & 327.5 & 1605 \\
\hline
\end{tabular}

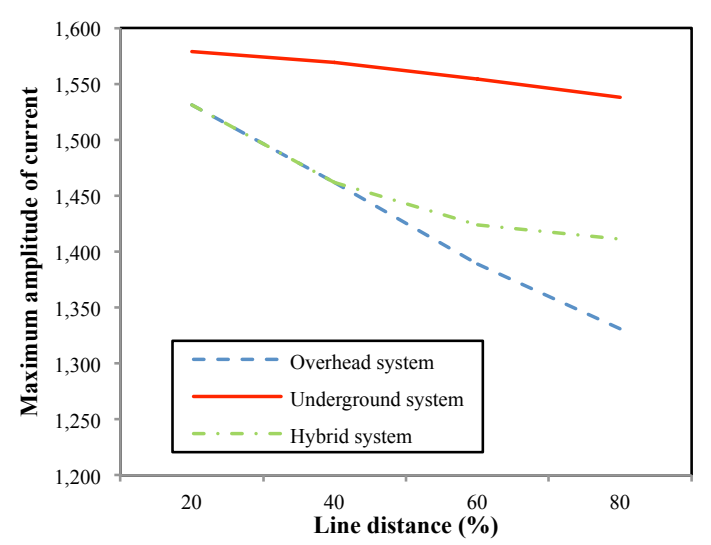

Fig. 6. Relation between maximum current and line distance in three case studied

By changing fault's angle as shown in Fig. 7 and Table 2 , which is case studies of single line to ground fault at $20 \%$ of line distance and fault's angle compared with phase A voltage at $60^{\circ}$. The trend of result is the same as fault's inception angle at $0^{\circ}$, illustrated in Fig. 2 , but the maximum current is higher than $0^{\circ}$ because of dc-component.

When comparing fault's inception angle at same angle and changed system, it is found that fault's current in case of underground system is the highest at $60^{\circ}$ which is 1.652 $\mathrm{A}$, and for overhead and hybrid system, the current is $1.605 \mathrm{~A}$.

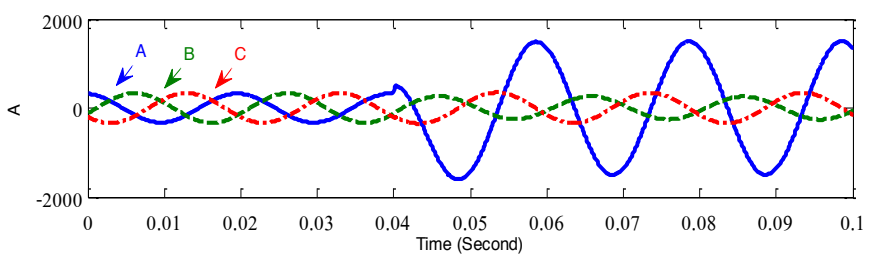

(a) Overhead system

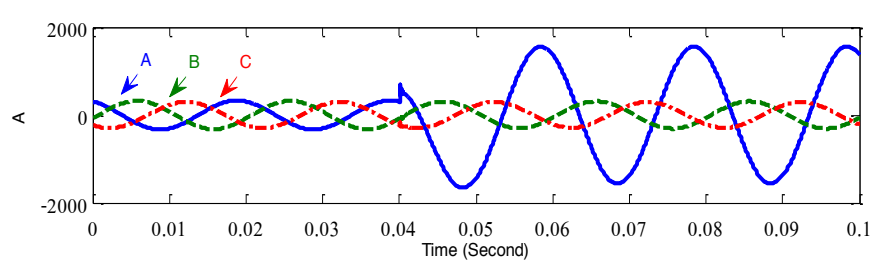

(b) Underground system

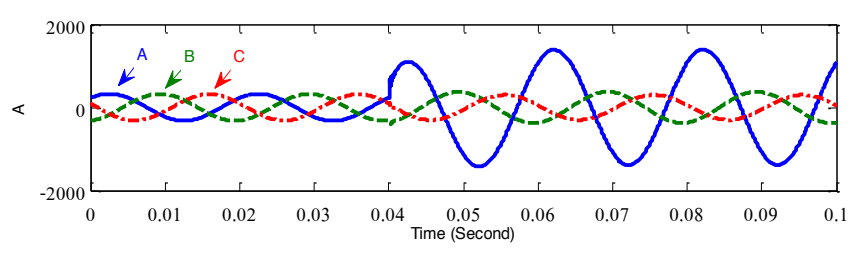

(c) Hybrid system

Fig. 7. fault inception angle at $60^{\circ}$ in single line to ground fault 


\section{Conclusions}

Presently, Thailand's distribution system has tried to change overall electrical power system from overhead system to hybrid system; this affects to protection system that needs to setup new system when fault's parameter change. This paper performed to study fault's characteristics in hybrid system and compared simulation result for overhead and underground systems in 2 cases. First was changing fault's position at $20 \%-80 \%$ of line distance and the second was changing fault's inception angle at $0^{\circ}$ and $60^{\circ}$. Both changing parameters are found that fault's current in each system was not similar because their system impedance was not equal. The further work will be the improvement for making protection system operation more correct; this needs to consider about characteristics of the overall system.

\section{References}

(1) H. Meyar-Naimi : "A new fuzzy fault locator for series compensated distribution lines", 11th International Conference on Environment and Electrical Engineering (EEEIC), May 2012, pp. 53 - 58.

(2) A. Bedoya-Cadena, C. Orozco-Henao, and J. Mora-Flórez : "Single Phase to Ground Fault Locator for Distribution Systems with Distributed Generation", Sixth IEEE/PES Transmission and Distribution: Latin America Conference and Exposition (T\&D-LA), 2012, pp. 1 - 7.

(3) Yadong Liu, Gehao Sheng, Xiaojun Shen, and Xiuchen Jiang : "Distributed Fault Location Based on Comprehensive Analysis of Fault Current", International Conference on Condition Monitoring and Diagnosis (CMD), 2012, pp. 999 - 1002.

(4) M. Pustulka, J. Izykowski, and M. Lukowicz : "Comparison of different approaches to arc fault location on power distribution lines", 12th International Conference on Environment and
Electrical Engineering (EEEIC), May 2013, pp. 145 149.

(5) Minn Thi Nguyet Dinh, M. Bahadornejad, A.S. Al Shahri, N.-K.C. Nair : "Protection schemes and fault location methods for multi-terminal lines: A comprehensive review", IEEE Innovative Smart Grid Technologies - Asia (ISGT Asia), Nov. 2013, pp. 1 - 6.

(6) Ravindra Kumar and Sanjiv Kumar : "A Novel Technique for Impedance Relay to Locate Fault in Long Distribution Line", Recent Advances in Engineering and Computational Sciences (RAECS), March 2014, pp. 1-6.

(7) Tzu-Chiao Lin, Pei-Yin Lin, and Chih-Wen Liu : "An Algorithm for Locating Faults in Three-Terminal Multisection Nonhomogeneous Distribution Lines Using Synchrophasor Measurements", IEEE Transactions on Smart Grid, Vol. 5, No. 1, Jan. 2014, pp. 38 - 50 .

(8) Chen Ping and Wang Kuixin : "Fault location technology for high-voltage overhead lines combined with underground power cables based on travelling wave principle", International Conference on Advanced Power System Automation and Protection (APAP), Vol. 1, Oct. 2011, pp. 748 - 751.

(9) F.V. Lopes, D. Fernandes, and W.L.A. Neves : "A Traveling-Wave Detection Generation Method Based on Park's Transformation for Fault Locators" IEEE Transactions on Power Delivery, Vol. 28, July 2013, pp. $1626-1634$.

(10)M. Abedini, A. Hasani, A.H. Hajbabaie, and V. Khaligh : "A new traveling wave fault location algorithm in series compensated distribution line", 21st Iranian Conference Electrical Engineering (ICEE), May 2013, pp. 1 - 6.

(11) Junyu Han, and P.A. Crossley : "Fault location on mixed overhead line and cable distribution networks", IEEE Grenoble PowerTech (POWERTECH), June 2013, pp. 1 - 6. 